\title{
THE EFFECT OF TAXATION ADMINISTRATION REFORM AND TAXATION KNOWLEDGE ON COMPLIANCE OF VAT ENTERPRISES
}

\begin{tabular}{ll} 
& $\begin{array}{c}\text { Abdul Hafiz Tanjung } \\
\text { Universitas Nasional Pasim, Bandung, Jawa Barat } \\
\text { hafiztanjung1970@gmail.com }\end{array}$ \\
& ABSTRAK/ABSTRACT \\
\hline INFO ARTIKEL & This research aims to give an overview about taxation \\
\hline Histori Artikel : & administration reform, taxtation knowledge and compliance \\
Tgl. Masuk : 31-01-2020 & taxable enterpreneur for VAT purposes descriptively, and \\
Tgl. Diterima : 12-03-2020 & whether there is or not an influence of taxation \\
Tersedia Online : 20-04-2020 & administration reform and taxtation knowledge towards \\
\hline Keywords: & compliance taxable enterpreneur for VAT Purposes on KPP \\
administration reform, taxtation & Pratama Cibeunying Kaler. Data used in this research was \\
knowledge, compliance & primer data collected by using questionnaire which was \\
& distributed to respondents. Respondent in this research is \\
& VAT Enterprises listed on KPP Pratama Cibeunying Kaler. \\
& Amount of samples obtained as many as 49 VAT \\
& Enterprises taken by method Simple Random Sampling \\
from 96 VAT Enterprises as a population. As for the \\
research method used was descriptive method and \\
associative. While the data analysis method is in this \\
research is Multiple Linear Regression Analysis. The result \\
of this research shows that taxation administration reform \\
and taxtation knowledge both partially and simultaneously \\
positive and significant effect to compliance Taxable \\
Enterpreneur for VAT Purposes on KPP Pratama \\
Cibeunying Kaler.
\end{tabular}

\section{PENDAHULUAN}

Pajak merupakan sumber dan tulang punggung utama penerimaan negara yang digunakan untuk membiayai pemerintahan dan pembangunan nasional dalam segala bidang, baik fisik maupun non fisik. Kelangsungan pembangunan nasional tersebut, tentu dan pasti pemerintah membutuhkan dana yang besar dan kebutuhan akan semakin meningkat seiring dengan adanya peningkatan kebutuhan pembangunan nasional.

Sumber dalam negeri yang paling potensial dan besar adalah penerimaan pajak yang berasal dari pajak penghasilan baik orang pribadi maupun badan, pajak pertambahan nilai dan pajak penjualan barang mewah. Berikut ini penerimaan pajak dalam negeri dari tahun 2015 sampai dengan 2019 :

Tabel 1

Penerimaan Pajak (Triliun Rupiah)
\begin{tabular}{|c|c|c|c|}
\hline $\begin{array}{c}\text { Tahu } \\
\mathrm{n}\end{array}$ & $\begin{array}{c}\text { Penerimaa } \\
\mathrm{n}\end{array}$ & $\begin{array}{c}\text { Kenaika } \\
\mathrm{n}\end{array}$ & $\begin{array}{c}\text { Keteranga } \\
\mathrm{n}\end{array}$ \\
\hline 2015 & $1.240,4$ & & Realisasi \\
\hline 2016 & $1.285,0$ & $3,6 \%$ & Realisasi \\
\hline 2017 & $1.472,7$ & $14,6 \%$ & Realisasi \\
\hline 2018 & $1.618,1$ & $10,0 \%$ & Realisasi \\
\hline 2019 & $1.786,4$ & $10,4 \%$ & Target \\
\hline
\end{tabular}

Sumber : kemenkeu.go.id/apbn2019 
Namun pada tahun 2019 realisasi penerimaan pajak yang telah diterima negara sampai dengan 31 Juli 2019 masih sebesar Rp. 810,7 triliun setara dengan 45,4\% dari target penerimaan Anggaran Pendapatan Belanja Negara (APBN) tahun 2019, tumbuh sebesar 3,9\% dari tahun 2018 namun jauh dibawah pertumbuhan tahun 2018 pada periode yang sama yaitu $14,6 \%$ (cnnindonesia).

Untuk selalu bisa meningkatkan penerimaan pajak, pemerintah republik Indonesia telah melakukan reformasi administrasi perpajakan. Reformasi administrasi perpajakan memudahkan Pengusaha Kena Pajak (PKP) dalam memenuhi kewajiban perpajakannya dengan begitu PKP akan lebih patuh melaksanakan kewajiban perpajakannya (Purnabhawa dan Aryani M, 2013), dengan kepatuhan tersebut diharapkan terjadi peningkatan penerimaan pajak oleh negara, dimana kita ketahui, realisasi penerimaan pajak sampai dengan semester satu tahun 2019 masih dibawah $50 \%$.

Disamping reformasi administrasi perpajakan, pengetahuan perpajakan juga diperlukan bagi seluruh wajib pajak. Pengetahuan perpajakan merupakan kemampuan seseorang (wajib pajak) dalam mengetahui seluruh aturan perpajakan baik itu mengenai tarif, waktu pembayaran dan pelaporan, serta hal lainnya sesuai dengan undang-undang pajak yang berlaku. Semakin baik pengetahuan perpajakan wajib pajak maka hal itu akan meningkatkan kepatuhan wajib pajak (Kemala, 2015).

Oleh karena itu, penelitian ini bertujuan untuk memberikan gambaran tentang reformasi administrasi perpajakan, pengetahuan perpajakan dan kepatuhan PKP serta melihat pengaruh reformasi administrasi perpajakan dan pengetahuan perpajakan terhadap kepatuhan PKP pada KPP Pratama Cibeunying Kaler, sehingga bisa memberikan manfaat bagi KPP tersebut secara khusus dan bagi dirjen pajak secara umumnya.

\section{KERANGKA TEORITIS}

Menurut Nasucha (2004:16), reformasi administrasi perpajakan merupakan suatu hal yang dilakukan dengan cara menyempurnakan atau memperbaiki kinerja administrasi secara individu, kelompok, serta kelembagaan sehingga menjadi lebih efisien, ekonomis, dan cepat. Selanjutnya Nasucha (2004) menjelaskan empat dimensi reformasi administrasi perpajakan, yaitu: struktur organisasi, prosedur organisasi, strategi organisasi, dan budaya organisasi. Dalam penelitian ini keempat dimensi tadi dikembangkan menjadi indikator dalam menggambar reformasi perpajakan pada KPP Pratama Cibeunying Kaler.

\begin{tabular}{llr}
\multicolumn{2}{c}{ Dengan adanya } & reformasi \\
administrasi & perpajakan & sehingga \\
pelayanan menjadi lebih efisien, \\
ekonomis, dan cepat diharapkan
\end{tabular} memberikan dampak positif terhadap kepatuhan wajib pajak. Hal ini sejalan dengan hasil penelitian terdahulu yang menunjukkan terdapat pengaruh positif reformasi administrasi perpajakan terhadap kepatuhan wajib pajak atau PKP yang diperlihatkan oleh hasil penelitian Punarbhawa dan Aryani M (2013), Rufaedah dan Hadiani (2015), dan hasil penelitian yang sama juga ditunjukkan oleh hasil penelitian Erviana Dewi dan Harta Mimba (2019). Berdasarkan uraian teoritis diatas, hipotesis penelitian satu dibangun sebagai berikut :

$\mathrm{H}_{1}$ : Reformasi adminitrasi perpajakan berpengaruh positif terhadap kepatuhan Pengusaha Kena Pajak di KPP Pratama Cibeunying Kaler. 
Pengertian pengetahun pajak menurut Caroline (2009:7) pengetahuan pajak adalah informasi yang dapat digunakan wajib pajak sebagai dasar bertindak, mengambil keputusan, dan untuk menempuh arah atau strategi tertentu sehubungan dengan pelaksanaan hak dan kewajibannya dibidang perpajakannya. Pengetahuan dapat diklasifikasikan menurut Caroline (2009) menjadi pengetahuan prosedural, dan pengetahuan deklaratif. Pengetahuan prosedural lebih menekankan pada bagaimana melakukan sesuatu. Pengetahuan deklaratif menjawab pertanyaan apakah sesuatu bernilai salah atau benar. Selanjutnya kedua klasifikasi pengetahuan ini menjadi dimensi yang dikembangkan menjadi indikator untuk mengukur pengetahuan perpajakan PKP yang terdaftar pada KPP Pratama Cibeunying Kaler.

Wajib Pajak yang memiliki pengetahuan perpajakan yang baik sudah tentu pengetahuan tersebut akan mendorongnya untuk memenuhi kewajiban perpajakan secara patuh atau sesuai dengan aturan perpajakan yang berlaku. Hasil penelitian terdahulu yang menggambarkan pengetahuan perpajakan berpengaruh positif terhadap kepatuhan wajib pajak atau pengusaha kena pajak diperlihatkan oleh hasil penelitian Punarbhawa dan Aryani M (2013), Susilawati dan Budiartha (2013) dan juga hasil penelitian Febriansyah (2015), dan Rahayu N (2017). Atas dasar uraian diatas, dalam penelitian ini hipotesis kedua yang dibangun adalah :

\section{$\mathrm{H}_{2}$ : Pengetahuan perpajakan berpengaruh positif terhadap kepatuhan Pengusaha Kena Pajak di KPP Pratama Cibeunying Kaler.}

\begin{abstract}
Menurut Rahayu SK (2006) Kepatuhan wajib pajak adalah Kepatuhan Wajib Pajak dalam mendaftarkan diri, kepatuhan untuk menyetorkan kembali SPT, kepatuhan dalam perhitungan dan pembayaran pajak terutang, kepatuhan dalam pembayaran tunggakan. Adapun jenis-jenis kepatuhan Wajib Pajak Rahayu SK (2006) adalah: 1. Kepatuhan formal adalah suatu keadaan dimana wajib pajak memenuhi kewajiban secara formal sesuai dengan ketentuan dalam Undang-undang perpajakan. 2. Kepatuhan material adalah suatu keadaan dimana wajib pajak secara substantif/hakikatnya memenuhi semua ketentuan material perpajakan.
\end{abstract}

Selanjutnya hasil penelitian yang menunjukkan reformasi administrasi perpajakan dan pengetahuan perpajakan secara bersama-sama berpengaruh positif terhadap kepatuhan wajib pajak atau pengusaha kena pajak diperlihat dari hasil penelitian Punarbhawa dan Aryani M (2013), sehingga dalam penelitian ini hipotesis ketiga yang diajukan adalah :

$\mathrm{H}_{3}$ : Reformasi administrasi perpajakan dan pengetahuan perpajakan berpengaruh positif terhadap kepatuhan Pengusaha Kena Pajak di KPP Pratama Cibeunying Kaler.

\section{RESEARCH METHODS Desain Penelitian}

Penelitian ini didesain menggunakan pendekatan deskriptif dan juga asosiatif. Pendekatan deskriptif digunakan untuk menggambarkan secara statistik deskriptif tentang reformasi administrasi perpajakan, pengetahuan perpajakan dan kepatuhan pengusahan kena pajak pada KPP Pratama Cibeunying Kaler. Sedangkan pendekatan asosiatif 
dilakukan untuk melihat pengaruh reformasi administrasi perpajakan dan pengetahuan perpajakan terhadap kepatuhan pengusaha kena pajak baik secara parsial maupun secara simultan pada KPP Pratama Cibeunying Kaler.

\section{Populasi dan Sampel}

Populasi dalam penelitian ini adalah seluruh Wajib Pajak Badan yang terdaftar di KPP Pratama Bandung Cibeunying Kaler yang juga merupakan Pengusaha Kena Pajak yang berukuran 96 PKP. Sedangkan untuk menentukan ukuran sampel, peneliti memakai rumus yang diturunkan oleh Yamane (1967) dengan tingkat presisi 0,10 dengan hasil perhitungan sampel berukuran 49 PKP. Peneliti memakai teknik penarikan sampel dengan metode sampling acak sederhana.

\section{Metode Pengumpulan Data}

Dalam penelitian ini peneliti menggunakan data primer, dimana data primer tersebut peneliti kumpulkan dengan menggunakan kuesioner. Kuesioner adalah sehimpunan pertanyaan yang telah dirancang terlebih dahulu dimana responden diberi alternatif pilihan jawaban yang sesuai dengan pendapatnya (Soedibjo, S. Bambang 2013:114).

\section{Instrumen Penelitian}

Dalam penelitian ini kuesioner digunakan sebagai instrumen penelitian. Kuesioner tersebut dibangun berdasarkan dimensi dari masing-masing variabel yang telah dijelaskan pada bagian telaah literatur dan pengembangan hipotesis. Untuk dimensi-dimensi pada variabel reformasi administrasi perpajakan diurai menjadi 15 indikator. Dimensi-dimensi pada variabel pengetahuan perpajakan diurai menjadi 10 indikator. Selanjutnya dimensi-dimensi pada variabel kepatuhan pengusaha kena pajak diurai menjadi 5 indikator.

Pilihan jawaban yang disediakan peneliti dalam kuesioner untuk variabel reformasi administrasi perpajakan adalah Sangat Baik (SB), Baik (B), Cukup Baik (CB), Tidak Baik (TB), Sangat Tidak Baik (STB), sedangkan pada variabel kepatuhan pengusaha kena pajak adalah Sangat Patuh (SP), Patuh (P), Cukup Patuh (CP), Tidak Patuh (TP), Sangat Tidak Patuh (STP).

Untuk merubah jawaban responden dari pilihan kualitatif menjadi kuantitatif, dalam penelitian ini peneliti menggunakan teknik penskalaan yaitu skala Likert. Menurut Sugiyono (2016:80) pengertian skala likert adalah : "Skala yang didesain untuk menguji kekuatan "setuju" atau "tidak setuju" subjek terhadap suatu pernyataan pada skala 5 titik, sehingga pilihan jawaban responden $\mathrm{SB} / \mathrm{SP}=5, \mathrm{~B} / \mathrm{P}=4$, $\mathrm{CB} / \mathrm{CP}=3, \mathrm{~KB} / \mathrm{KP}=2$, dan STB $/ \mathrm{SKP}=1$. Sedangkan untuk variabel pengetahuan perpajakan nilai jawaban yang diberikan jika jawaban benar diberi skor 10 sedangkan jawaban salah diberi skor 0 .

\section{Uji Reliabilitas dan Uji Validitas}

Untuk meyakinkan apakah instrumen penelitian (kuesioner) yang peneliti bangun dalam penelitian ini, benar-benar mengukur secara tepat variabel yang diteliti, peneliti telah melakukan uji reliabilitas dan uji validitas instrumen penelitian. Uji reliabilitas yang peneliti pilih adalah reliabilitas konsistensi antar butir dengan uji alpha Cronbach yang dikutip dari Soedibjo S. Bambang (2013), dengan ketentuan Sekaran (2003) reliabilitas kurang dari 0,6 menunjukkan bahwa instrumen dianggap kurang baik, sekitar 0,7 dikategorikan layak, jika lebih dari 0,8 dikategorikan baik. Adapun hasil uji reliabilitas dalam penelitian ini sebagai berikut:

Tabel 2 Hasil Uji Reliabilitas

\begin{tabular}{llll}
\hline N Variabe & $\begin{array}{l}\text { Cronba } \\
\text { ch's }\end{array}$ & $\begin{array}{l}\text { Keteran } \\
\text { gan }\end{array}$ \\
& Alpha & \\
& &
\end{tabular}

\begin{tabular}{rlll}
\hline & Reforma & & \\
& si \\
& Administ & & \\
rasi & & \\
& $\begin{array}{l}\text { Perpaja } \\
\text { kan }\end{array}$ & 0,906 & Baik \\
2 & $\begin{array}{l}\text { Pengeta } \\
\text { huan }\end{array}$ & 0,768 & Layak \\
& & &
\end{tabular}




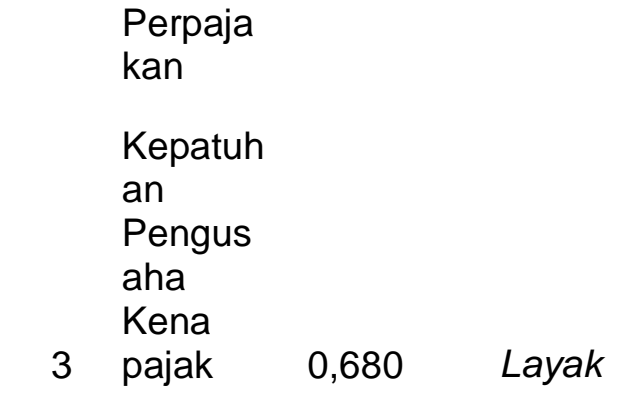

Sumber : Data primer diolah, 2019

Sedangkan uji validitas yang telah peneliti lakukan dalam penelitian ini menggunakan uji validitas konstruk yang dikutip dari Soedibjo S. Bambang (2013). Validitas konstruk ini dilakukan dengan cara menguji validitas dimensi terlebih dahulu, dengan cara mengkorelasikan antara total skor dimensi dengan total skor masing-masing variabel, lalu menguji validitas butir untuk masing-masing dimensi dengan cara mengkorelasi antara skor butir dengan total skor masingmasing dimensi. Kriteria yang digunakan oleh para peneliti yaitu dengan menetapkan nilai kritisnya sebesar 0,3 artinya jika koefisien korelasi bernilai $>0,3$, maka butir dinyatakan valid (Soedibjo, $\mathrm{S}$. Bambang 2013). Hasil uji validitas masing-masing dimensi dan butir untuk setiap variabel menunjukkan hasil valid.

\section{Metode Analisis Data}

Analisis data terbagi atas dua analisis yaitu analisis deskriptif dan analisis asosiatif. Analisis deskriptif terhadap jawaban responden pada masing-masing indikator dijelaskan dengan cara membuat persentase jawaban responden dengan membagi skor aktual dengan skor ideal. Metode analisis asosiatif yang digunakan dalam penelitian ini menggunakan pendekatan regresi linier berganda, dimana persamaan regresi linier berganda menurut Soedibjo $\mathrm{S}$. Bambang (2013 : 225) sebagai berikut:

$$
Y^{\prime}=\beta o+\beta_{1} X_{1}+\beta_{2} X_{2+} e
$$

Keterangan:

$$
\begin{array}{rlr}
Y^{\prime} & =\begin{array}{l}
\text { Kepatuhan Pengusaha } \\
\text { Kena Pajak }
\end{array} \\
\beta_{0}= & \text { Konstanta } \\
\beta_{1}= & \begin{array}{l}
\text { Koefisien Regresi } \\
\text { Reformasi Administrasi }
\end{array} \\
& & \begin{array}{l}
\text { Perpajakan } \\
\beta_{2}=
\end{array} \\
& \text { Koefisien } & \begin{array}{l}
\text { Pengetahuan } \\
\text { Regresi }
\end{array} \\
\mathrm{X}_{1}= & \begin{array}{l}
\text { Perpajakan } \\
\text { Reformasi Administrasi }
\end{array} \\
\mathrm{X}_{2}= & \begin{array}{l}
\text { Perpajakan } \\
\text { Pengetahuan }
\end{array} \\
e & \begin{array}{l}
\text { Perpajakan } \\
\text { Variabel Pengangguran } \\
\text { (tidak dihitung) }
\end{array}
\end{array}
$$

Analisis linier berganda digunakan setelah terlebih dahulu dilakukan uji asumsi klasik yaitu : 1) Uji normalitas dengan kolmogorov-smirnov dengan tingkat signifikan 0,05 dengan ketentuan Asymp.Sig (2-tailed) lebih besar dari 0,05 menunjukkan data berdistribusi normal. Hasil uji menunjukkan Asymp.Sig (2-tailed) sebesar 0,786 >0,05 sehingga data dinyatakan berdistibusi normal. 2) Uji multikolinearitas dengan menggunakan Variance Inflation Factors (VIF) dengan ketentuan yang umum dipakai untuk menunjukkan adanya multikolinieritas adalah jika nilai tolerance $<0,10$ atau sama dengan nilai VIF > 10. Dalam penelitian ini hasil uji menunjukkan untuk variabel reformasi administrasi perpajakan nilai tolerance sebesar $0,520>0,10$ dan VIF sebesar $1,924<10$, variabel pengetahuan perpajakan nilai tolerance sebesar 0,520 >0,10 dan VIF sebesar $1,924<10$ sehingga bisa dikatakan tidak terjadi multikolinieritas, serta 3 ). Uji heteroskedastisitas, cara yang akan digunakan untuk melakukan uji heterokedastisitas dalam penelitian ini adalah dengan melihat grafik plot antara nilai prediksi variabel terikat (dependen) 
yaitu ZPRED dengan residualnya SRESID. Deteksi ada tidaknya heterokedastisitas dapat dilakukan dengan melihat ada tidaknya pola tertentu pada grafik scatterplot antara SRESID dan ZPRED, dimana sumbu $Y$ adalah $Y$ yang telah diprediksi, dan sumbu $X$ adalah residual ( $Y$ prediksi - $Y$ sesungguhnya) yang telah di-studentized dengan dasar analisis:

1. Jika ada pola tertentu, seperti titik-titik yang ada membentuk pola tertentu yang teratur (bergelombang, melebar kemudian menyempit), maka mengindikasikan telah terjadi heterokedastisitas.

2. Jika tidak ada pola yang jelas, serta titik-titik menyebar diatas dan dibawah angka 0 pada sumbu $\mathrm{Y}$, maka tidak terjadi heterokedastisitas.

Hasil Uji Heterokedastisitas untuk penelitian ini terlihat seperti gambar berikut:

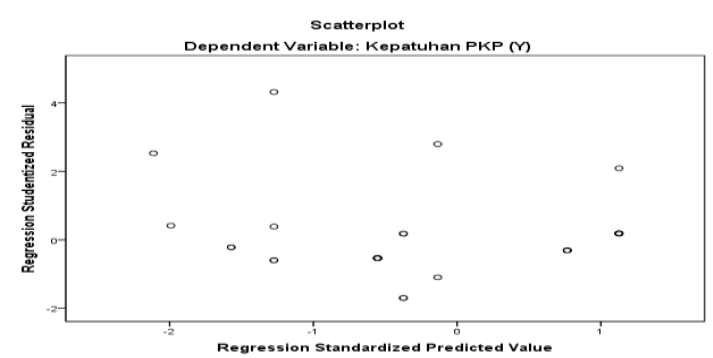

\section{Gambar 1 Hasil Uji Heteroskedastisitas}

\section{Sumber : data primer diolah, 2019}

$\begin{array}{rrrr}\text { Gambar } 1 & \text { merupakan } & \text { grafik } \\ \text { scatterplot dari } & \text { hasil } & \text { uji }\end{array}$ heteroskedastisitas pada data penelitian ini, dari gambar tersebut menunjukkan bahwa data tersebar secara acak dan tidak membentuk suatu pola tertentu. Data tersebar baik di atas maupun dibawah angka 0 pada sumbu $Y$. Hal ini menunjukkan bahwa tidak terdapat gejala heteroskedastisitas dalam data penelitian ini.

\section{Uji Signifikan}

Pengujian hipotesis untuk melihat signifikan atau tidak pengaruh masingmasing variabel reformasi administrasi perpajakan dan pengetahuan perpajakan terhadap variabel kepatuhan pengusaha kena pajak digunakan uji $t$, menurut Soedibjo S. Bambang (2013 : 207) uji t digunakan dengan ketentuan derajat bebas $=n-2$ dan taraf signifikan 0,05 jika $t$ hitung $>t$ tabel tolak $\mathrm{H}_{0}$ artinya terdapat pengaruh signifikan. Sedangkan untuk pengujian hipotesis secara simultan pengaruh variabel reformasi administrasi perpajakn dan pengetahuan perpajakan terhadap kepatuhan pengusaha kena pajak digunakan uji $F$, menurut Soedibjo $S$. Bambang (2013 :228) uji $F$ digunakan dengan ketentuan derajat bebas untuk MSR adalah $v_{1}=p$ dan untuk MSE adalah $v_{2}=(n-p-1)$ dan taraf signifikan 0,05, jika $\mathrm{F}$ hitung $>\mathrm{F}$ tabel tolak $\mathrm{H}_{0}$ artinya terdapat pengaruh signifikan secara simultan.

\section{HASIL \& PEMBAHASAN}

\section{Analisis Deskriptif Reformasi \\ Administrasi Perpajakan di KPP Pratama Cibeunying Kaler}

Reformasi administrasi perpajakan dalam penelitian ini diambil dari teori yang dikembangkan Nasucha (2004), dimana ada empat dimensi reformasi administrasi perpajakan, yaitu: struktur organisasi, prosedur organisasi, strategi organisasi, dan budaya organisasi. Dalam penelitian ini keempat dimensi tadi dituangkan dalam kuesioner yang terdiri dari 15 butir pernyataan untuk menggambar reformasi perpajakan pada KPP Pratama Cibeunying Kaler. Intisari hasil kuesioner tentang reformasi perpajakan pada KPP Pratama 
Cibeunying Kaler menurut responden penelitian ini dijelaskan dalam tabel berikut

Tabel 3

Data jawaban responden terhadap masingmasing dimensi pada Reformasi Administrasi Perpajakan

\begin{tabular}{|c|c|c|c|c|c|c|c|c|}
\hline \multirow{2}{*}{$\begin{array}{l}\mathrm{N} \\
\mathrm{O}\end{array}$} & \multicolumn{5}{|c|}{$\begin{array}{l}\text { Tanggapan } \\
\text { Responden }\end{array}$} & \multicolumn{2}{|c|}{ Skor } & \multirow{2}{*}{$\begin{array}{l}\text { Perse } \\
\text { ntase }\end{array}$} \\
\hline & $\begin{array}{c}\text { ST } \\
\text { B }\end{array}$ & $\begin{array}{l}\mathrm{T} \\
\mathrm{B}\end{array}$ & $\begin{array}{l}\text { C } \\
\text { B }\end{array}$ & $B$ & $\begin{array}{l}S \\
B\end{array}$ & $\begin{array}{l}\text { Akt } \\
\text { ual }\end{array}$ & $\begin{array}{c}\text { ld } \\
\text { ea } \\
\text { l }\end{array}$ & \\
\hline 1 & & & & $\begin{array}{l}1 \\
7\end{array}$ & $\begin{array}{l}3 \\
2\end{array}$ & $\begin{array}{c}22 \\
8\end{array}$ & $\begin{array}{c}24 \\
5\end{array}$ & $\begin{array}{c}93.10 \\
\%\end{array}$ \\
\hline 2 & & & 3 & $\begin{array}{l}2 \\
1\end{array}$ & $\begin{array}{l}2 \\
5\end{array}$ & $\begin{array}{c}21 \\
8\end{array}$ & $\begin{array}{c}24 \\
5\end{array}$ & $\begin{array}{c}89.00 \\
\%\end{array}$ \\
\hline 3 & & & & $\begin{array}{l}1 \\
2\end{array}$ & $\begin{array}{l}3 \\
7\end{array}$ & $\begin{array}{c}23 \\
3\end{array}$ & $\begin{array}{c}24 \\
5\end{array}$ & $\begin{array}{c}95.10 \\
\%\end{array}$ \\
\hline 4 & & & $\begin{array}{l}2 \\
0\end{array}$ & $\begin{array}{l}1 \\
3\end{array}$ & $\begin{array}{l}1 \\
6\end{array}$ & $\begin{array}{c}19 \\
2\end{array}$ & $\begin{array}{c}24 \\
5\end{array}$ & $\begin{array}{c}78.40 \\
\%\end{array}$ \\
\hline & a-ra & $\mathrm{dir}$ & ens & tru & ur & gani & & $\begin{array}{c}88.90 \\
\%\end{array}$ \\
\hline 5 & & & 4 & $\begin{array}{l}4 \\
5\end{array}$ & & $\begin{array}{r}19 \\
2\end{array}$ & $\begin{array}{r}24 \\
5\end{array}$ & $\begin{array}{c}78.40 \\
\%\end{array}$ \\
\hline 6 & & & & $\begin{array}{l}2 \\
4\end{array}$ & $\begin{array}{l}2 \\
5\end{array}$ & $\begin{array}{r}22 \\
5\end{array}$ & $\begin{array}{r}24 \\
5\end{array}$ & $\begin{array}{c}91.80 \\
\%\end{array}$ \\
\hline 7 & & & 1 & 9 & $\begin{array}{l}3 \\
9\end{array}$ & $\begin{array}{r}23 \\
4\end{array}$ & $\begin{array}{r}24 \\
5\end{array}$ & $\begin{array}{c}95.50 \\
\%\end{array}$ \\
\hline 8 & & & & $\begin{array}{l}1 \\
9\end{array}$ & $\begin{array}{l}3 \\
0\end{array}$ & $\begin{array}{r}22 \\
6\end{array}$ & $\begin{array}{r}24 \\
5\end{array}$ & $\begin{array}{c}92.20 \\
\%\end{array}$ \\
\hline & a-rat & $\operatorname{dim}$ & nsi & ros & dur & rgan & & $\begin{array}{c}89.50 \\
\%\end{array}$ \\
\hline 9 & & & & $\begin{array}{l}2 \\
4\end{array}$ & $\begin{array}{l}2 \\
5\end{array}$ & $\begin{array}{r}22 \\
1\end{array}$ & $\begin{array}{r}24 \\
5\end{array}$ & $\begin{array}{c}90.20 \\
\%\end{array}$ \\
\hline $\begin{array}{l}1 \\
0\end{array}$ & & & & $\begin{array}{l}1 \\
2\end{array}$ & $\begin{array}{l}3 \\
7\end{array}$ & $\begin{array}{r}23 \\
3\end{array}$ & $\begin{array}{r}24 \\
5\end{array}$ & $\begin{array}{c}95.10 \\
\%\end{array}$ \\
\hline $\begin{array}{l}1 \\
1\end{array}$ & & & $\begin{array}{l}2 \\
0\end{array}$ & $\begin{array}{l}1 \\
3\end{array}$ & $\begin{array}{l}1 \\
6\end{array}$ & $\begin{array}{r}19 \\
2\end{array}$ & $\begin{array}{r}24 \\
5\end{array}$ & $\begin{array}{c}78.40 \\
\%\end{array}$ \\
\hline $\begin{array}{l}1 \\
2\end{array}$ & & & & $\begin{array}{l}1 \\
4\end{array}$ & $\begin{array}{l}3 \\
5\end{array}$ & $\begin{array}{r}23 \\
1\end{array}$ & $\begin{array}{r}24 \\
5\end{array}$ & $\begin{array}{c}94.30 \\
\%\end{array}$ \\
\hline
\end{tabular}

\begin{tabular}{|l|l|l|r|r|r|r|r|r|}
\hline \multicolumn{7}{|c|}{ Rata-rata dimensi strategi organisasi } & $\begin{array}{c}89.50 \\
\%\end{array}$ \\
\hline 1 & & & 4 & 4 & 2 & 19 & 24 & $79,2 \%$ \\
\hline 1 & & & & 1 & 3 & 23 & 24 & $95,1 \%$ \\
4 & & & 2 & 7 & 3 & 5 & \\
\hline 1 & & & & 1 & 3 & 23 & 24 & $93,9 \%$ \\
5 & & & 5 & 0 & 5 & \\
\hline \multicolumn{7}{|c|}{ Rata-rata dimensi budaya organisasi } & $89,4 \%$ \\
\hline \multicolumn{7}{|c|}{ Rata-rata variabel reformasi } \\
administrasi perpajakan \\
\hline
\end{tabular}

Sumber : data primer, diolah 2019

Berdasarkan data pada tabel 3 tadi, pada dimensi struktur organisasi secara keseluruhan rata-rata nilai indikator adalah $88,9 \%$ artinya reformasi administrasi perpajakan pada dimensi struktur organisasi dinilai oleh responden telah berjalan $88,9 \%$, hanya pada pernyataan no 4 yaitu indikator jaringan komunikasi dinilai oleh responden sebesar $78,40 \%$, hal ini ditunjukkan oleh 20 orang responden yang menjawab "cukup baik". Pada dimensi prosedur organisasi secara keseluruhan rata-rata nilai dari indikator adalah $89.5 \%$, artinya reformasi administrasi perpajakan pada dimensi prosedur organisasi dinilai oleh responden telah berjalan $89,5 \%$, hanya pada pernyataan no 5 yaitu indikator prosedur pelayanan dinilai oleh responden sebesar $78,40 \%$ karena mayoritas responden memberi jawaban baik dan ada 4 responden menjawab cukup baik dan tidak ada sangat baik.

Selanjutnya pada dimensi strategi organisasi secara keseluruhan rata-rata nilai dari indikator adalah $89.5 \%$, artinya reformasi administrasi perpajakan pada dimensi strategi organisasi dinilai oleh responden telah berjalan $89,5 \%$, hanya pada pernyataan no 11 yaitu indikator tata cara perpajakan masih ada 20 responden 
menjawab cukup baik. Pada dimensi terakhir yaitu dimensi budaya organisasi secara keseluruhan rata-rata nilai dari dimensi budaya organisasi adalah $89.4 \%$, dan nilai terendah berada pada pernyataan no 13 yaitu indikator perilaku petugas sebesar $79,2 \%$. Keseluruhan dimensi pada variabel reformasi administrasi perpajakan yang menggambarkan variabel yang bersangkutan dinilai oleh responden $89,31 \%$ berjalan dengan sangat baik.

Analisis

Deskriftif Pengetahuan Perpajakan PKP di KPP Pratama Cibeunying Kaler

Data tentang pengetahuan perpajakan diperoleh dari kuesioner yang disebar kepada responden di KPP Pratama Cibeunying Kaler dengan jumlah item 10 pertanyaan. Pengetahuan perpajakan yang diukur dalam penelitian ini menggunakan 2 dimensi. Hasilnya dijelaskan dalam tabel sebagai berikut :

Tabel 4

Data jawaban responden pada setiap pernyataan mengenai Pengetahuan perpajakan

\begin{tabular}{|c|c|c|c|c|c|}
\hline \multirow{2}{*}{$\begin{array}{c}\text { No. Item } \\
\text { Pertany } \\
\text { aan }\end{array}$} & \multicolumn{2}{|c|}{$\begin{array}{l}\text { Jawaban } \\
\text { Responden }\end{array}$} & \multicolumn{2}{|c|}{ Skor } & \multirow{2}{*}{$\begin{array}{c}\text { Persent } \\
\text { ase }\end{array}$} \\
\hline & Salah & Benar & $\begin{array}{c}\text { Aktu } \\
\text { al }\end{array}$ & $\begin{array}{l}\text { Ide } \\
\text { al }\end{array}$ & \\
\hline 1 & 1 & 48 & 480 & 49 & $98,0 \%$ \\
\hline 2 & 1 & 48 & 480 & $\begin{array}{c}49 \\
0\end{array}$ & $98,0 \%$ \\
\hline 3 & 1 & 48 & 480 & $\begin{array}{c}49 \\
0\end{array}$ & $98,0 \%$ \\
\hline 4 & 2 & 47 & 470 & $\begin{array}{c}49 \\
0\end{array}$ & $95,9 \%$ \\
\hline 5 & 2 & 47 & 470 & $\begin{array}{c}49 \\
0\end{array}$ & $95,9 \%$ \\
\hline 6 & 1 & 48 & 480 & $\begin{array}{c}49 \\
0\end{array}$ & $98,0 \%$ \\
\hline Rata-rata & imensi p & ggetahu & pros & ural & $97.30 \%$ \\
\hline
\end{tabular}

\begin{tabular}{|c|r|r|r|r|r|}
\hline 7 & 2 & 47 & 470 & $\begin{array}{c}49 \\
0\end{array}$ & $95,9 \%$ \\
\hline 8 & 2 & 47 & 470 & $\begin{array}{c}49 \\
0\end{array}$ & $95,9 \%$ \\
\hline 9 & 22 & 27 & 270 & $\begin{array}{c}49 \\
0\end{array}$ & $55,1 \%$ \\
\hline 10 & 1 & 48 & 480 & $\begin{array}{c}49 \\
0\end{array}$ & $98,0 \%$ \\
\hline \multicolumn{4}{|r|}{ Rata-rata dimensi pengetahuan deklaratif } & $\mathbf{8 6 . 2 2 \%}$ \\
\hline \multicolumn{3}{|r|}{ perpajakan } \\
\hline
\end{tabular}

Sumber : Data primer, diolah 2019

Berdasarkan data pada tabel 4 diatas, penjelasan terhadap angka-angka yang adalah sebagai berikut : pada dimensi pengetahuan prosedural terdapat 6 pertanyaan yang ditanyakan. Secara keseluruhan rata-rata nilai dari dimensi pengetahuan prosedural adalah $97,3 \%$. Pada dimensi ini tidak terdapat nilai dibawah $80 \%$, hal ini ditunjukkan oleh hasil yang menyatakan bahwa secara mayoritas atau bahkan secara keseluruhan responden mampu menjawab pertanyaan yang diberikan dengan "sangat baik". Sedangkan pada diimensi pengetahuan deklaratif secara keseluruhan rata-rata nilai dari dimensi ini adalah $86,22 \%$, dan nilai terendah berada pada pertanyaan no 9 yaitu sebesar $55,1 \%$, hal ini ditunjukkan oleh 22 orang responden yang menjawab "salah" pada pertanyaan "WP badan yang tidak melakukan kegiatan usaha lagi tetapi belum dibubarkan sesuai dengan ketentuan yang berlaku dan tidak melaporkan SPT. Apakah terkena denda atau tidak", sedangkan pada pertanyaan lain secara mayoritas atau bahkan secara keseluruhan responden mampu menjawab dengan "benar". Keseluruhan variabel pengetahuan perpajakan PKP rata-rata nilainya sebesar $91,76 \%$, hal ini 
menunjukkan pengetahuan perpajakan yang sangat baik.

Analisis Deskriptif Kepatuhan PKP di KPP Pratama Cibeunying Kaler

Data tentang kepatuhan PKP diperoleh dari kuesioner yang disebar kepada responden di KPP Pratama Cibeunying Kaler dengan jumlah item 5 pernyataan. Kepatuhan perpajakan yang diukur dalam penelitian ini menggunakan 2 dimensi. Untuk lebih rinci dijelaskan sebagai berikut :

\section{Tabel 5}

Data jawaban responden pada setiap pernyataan mengenai

Kepatuhan PKP

\begin{tabular}{|c|c|c|c|c|c|c|c|c|}
\hline \multirow{2}{*}{$\begin{array}{l}\mathrm{N} \\
\mathrm{o} .\end{array}$} & \multicolumn{5}{|c|}{ Tanggapan Responden } & \multicolumn{2}{|c|}{ Skor } & \multirow{2}{*}{$\begin{array}{c}\text { Persent } \\
\text { ase }\end{array}$} \\
\hline & $\begin{array}{c}\text { ST } \\
\text { P }\end{array}$ & $\begin{array}{l}\mathrm{T} \\
\mathrm{P}\end{array}$ & $\begin{array}{l}C \\
P\end{array}$ & P & $\begin{array}{l}S \\
P\end{array}$ & $\begin{array}{c}\text { Aktu } \\
\text { al }\end{array}$ & $\begin{array}{l}\text { Ide } \\
\text { al }\end{array}$ & \\
\hline 1 & & & 6 & $\begin{array}{l}4 \\
1\end{array}$ & 2 & 192 & $\begin{array}{c}24 \\
5\end{array}$ & $78,4 \%$ \\
\hline 2 & & & $\begin{array}{l}2 \\
3\end{array}$ & $\begin{array}{l}2 \\
5\end{array}$ & 1 & 174 & $\begin{array}{c}24 \\
5\end{array}$ & $71,0 \%$ \\
\hline 3 & & & $\begin{array}{l}2 \\
7\end{array}$ & $\begin{array}{l}2 \\
1\end{array}$ & 1 & 170 & $\begin{array}{c}24 \\
5\end{array}$ & $69,4 \%$ \\
\hline \multicolumn{8}{|c|}{$\frac{1}{R a t a-r a t a}$ dimensi kepatuhan formal } & $72,9 \%$ \\
\hline 5 & & & $\begin{array}{l}1 \\
9\end{array}$ & $\begin{array}{l}2 \\
8\end{array}$ & 2 & 179 & $\begin{array}{r}24 \\
5\end{array}$ & $73,1 \%$ \\
\hline 6 & & & $\begin{array}{l}1 \\
5\end{array}$ & $\begin{array}{l}3 \\
3\end{array}$ & 1 & 182 & $\begin{array}{r}24 \\
5\end{array}$ & $74,3 \%$ \\
\hline \multicolumn{8}{|c|}{ Rata-rata dimensi kepatuhan material } & $73,67 \%$ \\
\hline & Rata & ata & arial & el k & atu & an PK & & $73,30 \%$ \\
\hline
\end{tabular}

Sumber : data primer, diolah 2019

Berdasarkan data pada tabel 5 tadi, peneliti dapat jelaskan sebagai berikut: pada dimensi kepatuhan formal terdapat 3 pernyataan yang ditanyakan. Secara keseluruhan rata-rata nilai dari dimensi kepatuhan formal adalah $72,9 \%$, dan nilai terendah berada pada pernyataan no 3 yaitu sebesar $69,4 \%$, hal ini ditunjukkan oleh 27 orang responden yang menyatakan "cukup baik" pada pernyataan "Dalam menghitung pajak yang terutang sesuai peraturan pajak, saya termasuk PKP ....", sedangkan pada pernyataan lain secara mayoritas atau bahkan secara keseluruhan responden menyatakan "baik" dan "sangat baik".

Sedangkan pada dimensi kepatuhan material terdapat 2 pernyataan yang ditanyakan. Secara keseluruhan rata-rata nilai dari dimensi kepatuhan material adalah $73,67 \%$. Keseluruhan variabel kepatuhan pengusaha kena pajak nilainya sebesar 73,30\% artinya kepatuhan pengusaha kena pajak sudah baik akan tetapi belum sangat baik.

\section{Hasil Pengujian Hipotesis}

Berikut ini tabel yang menyajikan hasil perhitungan regresi linier berganda untuk melihat besarnya pengaruh masingmasing variabel independen terhadap variabel dependen.

\section{Tabel 6}

\section{Hasil Perhitungan Regresi Linier Berganda}

\begin{tabular}{|c|c|c|c|c|}
\hline \multirow{2}{*}{ Variabel } & \multicolumn{2}{|c|}{$\begin{array}{c}\text { Koefisien } \\
\text { Regresi }\end{array}$} & t & Sig \\
\cline { 2 - 4 } & B & Std. Error & & \\
\hline Konstanta & 3,047 & 2,188 & 1,393 & 0,170 \\
\hline $\begin{array}{c}\text { Reformasi Adm } \\
\text { Perpajakan }\end{array}$ & 0,145 & 0,045 & 3,216 & 0,002 \\
\hline $\begin{array}{c}\text { Pengetahuan } \\
\text { Perpajakan }\end{array}$ & 0,060 & 0,024 & 2,465 & 0,018 \\
\hline Sig F & 0,000 & F hitung & 26,997 \\
\hline$R^{2}$ & 0,534 & $\begin{array}{c}\text { Adjusted } \\
R^{2}\end{array}$ & \multicolumn{2}{|c|}{0,514} \\
\hline
\end{tabular}

Sumber : Data primer diolah, 2019

Berdasarkan pada tabel 6 tersebut, koefisien regresi untuk variabel reformasi administrasi perpajakan diperoleh sebesar 0,145 , nilai koefisien ini yang menunjukkan besarnya pengaruh positif reformasi administrasi perpajakan terhadap kepatuhan pengusaha kena pajak. Artinya jika variabel reformasi administrasi 
perpajakan meningkat sebesar 0,145 maka variabel kepatuhan pengusaha kena pajak akan meningkat sebesar 0,145 pula dengan asumsi variabel lain konstan. Pengujian hipotesis untuk melihat apakah pengaruh variabel reformasi administrasi perpajakan terhadap variabel kepatuhan pengusaha kena pajak menunjukkan pengaruh yang signifikan atau tidak, hal ini dapat dilihat dari nilai $t$ hitung sebesar 3,216 > t tabel sebesar 2,013 dengan derajat bebas $(\mathrm{df}=\mathrm{n}-\mathrm{k}-1$ ) atau $49-2-1=46$ dan taraf signifikan $\frac{0,05}{2}=0,025$ (uji dua sisi), hasil ini membukti hipotesis kesatu yang diajukan dapat diterima. Hasil penelitian ini sejalan dengan hasil penelitian Punarbhawa dan Aryani M (2013), Rufaedah dan Hadiani (2015), dan hasil penelitian Erviana Dewi dan Harta Mimba (2019) yang menunjukkan terdapat pengaruh positif signifikan reformasi administrasi perpajakan terhadap kepatuhan wajib pajak atau pengusaha kena pajak.

Selanjutnya, koefisien regresi untuk variabel pengetahuan perpajakan berdasar tabel 6 diatas sebesar 0,060, koefisien regresi inilah yang menunjukkan besarnya pengaruh positif variabel pengetahuan perpajakan terhadap variabel kepatuhan pengusaha kena pajak, artinya jika pengetahuan perpajakan meningkat sebesar 0,060 maka kepatuhan pengusaha kena pajak akan meningkat pula sebesar 0,060 dengan asumsi variabel lain konstan. Dari hasil pengujian hipotesis menunjukkan koefisien regresi ini signifikan, hal ini dapat dilihat dari nilai t hitung sebesar 2,465 >t tabel sebesar 2,013 dengan derajat bebas (df $=n-k-1)$ atau 49-2-1=46 dan taraf signifikan $\frac{0,05}{2}=0,025$ (uji dua sisi), hasil ini membukti hipotesis kedua yang diajukan juga dapat diterima. Hasil penelitian ini sejalan dengan hasil penelitian terdahulu yaitu Punarbhawa dan Aryani M (2013), Susilawati dan Budiartha (2013) dan juga hasil penelitian Febriansyah (2015), dan Rahayu N (2017) yang menyatakan bahwa pengetahuan perpajakan berpengaruh positif dan signifikan terhadap kepatuan pengusaha kena pajak.

Besarnya pengaruh bersamasama variabel independen terhadap variabel dependen dapat dilihat dari nilai $\mathrm{R}^{2}$ sebesar 0,534 (lihat tabel 6). Hal menunjukkan bahwa sebesar 53,4\% variabel kepatuhan pengusaha kena pajak dapat dijelaskan oleh variabel reformasi administrasi perpajakan dan pengetahuan perpajakan secara bersama-sama. Besarnya pengaruh bersama-sama ini juga signifikan, hal ini ditunjukkan dari besar nilai $F$ hitung sebesar 26,997 > dari nilai $F$ tabel 2,84 dengan derajat bebas $v_{1}$ = 3 dan $\mathrm{v}_{2}=49-3-1=45$ dengan taraf signifikan 0,05 . Hasil penelitian ini sejalan dengan hasil penelitian terdahulu Punarbhawa dan Aryani M (2013) yang menyatakan reformasi administrasi perpajakan dan pengetahuan perpajakan secara bersama-sama berpengaruh terhadap kepatuhan pengusaha kena pajak.

\section{KESIMPULAN}

Berdasarkan hasil analisis data dan pembahasan yang telah diuraikan sebelumnya, maka dapat ditarik kesimpulan yaitu reformasi administrasi perpajakan dan pengetahuan perpajakan baik secara parsial maupun secara simultan memiliki pengaruh positif terhadap kepatuhan pengusaha kena pajak. Semakin baik reformasi administrasi perpajakan dan pengetahuan perpajakan pengusaha kena pajak, maka akan semakin baik pula kepatuhan mereka. Besarnya pengaruh bersamasama dari dua variabel independen ini hanya $53,4 \%$ sisanya dipengaruhi oleh factor-faktor lain yang tidak diteliti dalam penelitian ini. 
Hasil penelitian ini juga menunjukkan reformasi administrasi perpajakan sudah sangat baik di KPP Pratama Cibeunying Kaler, begitu juga pengetahuan perpajakan pengusaha kena pajak yang terdaftar pada KPP Pratama Cibeunying Kaler sudah masuk dalam kategori sangat baik. Namun kepatuhan pengusaha kena pajak yang terdaftar pada KPP Pratama Cibeunying Kaler masih masuk kategori patuh atau cukup patuh. Hasil penelitian ini mengimplikasikan adanya factor-faktor lain yang menyebabkan kepatuhan pengusaha kena pajak tidak sampai pada tingkat sangat patuh.

Keterbatasan penelitian ini hanya dilakukan pada KPP Pratama Cibeunying Kaler, dan merupakan salah satu dari sekian banyak KPP Pratama yang ada di jawa barat bahkan Indonesia, sehingga hasil penelitian ini belum tentu mencerminkan untuk seluruh KPP Pratama yang ada di jawa barat bahkan Indonesia.

Saran yang dapat diberikan bagi peneliti selanjutnya yaitu melakukan penelitian lebih lanjut tidak terbatas hanya pada variabel reformasi administrasi perpajakan dan pengetahuan perpajakan yang dikaitkan dengan tingkat kepatuhan pengusaha kena pajak, namun menambahkan variabel lainnya yang berkaitan dengan tingkat kepatuhan, karena kedua variabel independen yang diteliti dalam penelitian ini hanya berpengaruh $53,4 \%$ saja, juga memperluas cakupan KPP Pratama yang akan diteliti supaya hasilnya lebih menggambarkan keadaaan sebenarnya pada KPP Pratama yang ada di jawa barat

\section{REFERENCES}

Caroline, V. (2009). Pengetahuan pajak. Jakarta : Salemba Empat
Erviana Dewi, I. G. A. P. dan Harta Mimba, N. P. S. (2019). Pengaruh Reformasi Administrasi Perpajakan dan Tax Amnesty Terahadap Kepatuhan WPOP dengan Preferensi Risiko sebagai Pemoderasi, e-Jurnal Akuntansi Universitas Udayana. Vol.26, Halaman : 2210-2239.

Febriansyah, A. (2015). Analisis Pengaruh Kualitas Pelayanan dan Pengetahuan Perpajakan terhadap Kepatuhan Wajib Pajak Orang Pribadi pada KPP Pratama Bandung Cicadas. Jurnal Riset Akuntansi. Vol. VII. No.2. https://www.cnnindonesia.com/eko nomi/20190827102723-532424925/lesu-penerimaanperpajakan-baru-capai-45-persen Kemenkeu.go.id/apbn2019

Kemala, W. (2015). Pengaruh Kesadaran Wajib Pajak, Pengetahuan Pajak, Sikap wajib Pajak, dan Reformasi Administrasi Perpajakan Terhadap Kepatuhan Wajib Pajak Kendaraan Bermotor. JOM.FEKON. Vol.2 No.1 Februari 2015.

Nasucha, C. (2004). Reformasi Administrasi Publik: Teori dan Praktik. Jakarta : PT Gramedia Widiasarana Indonesia.

Punarbhawa, I. G. A. B. dan Aryani, M. N. K. (2013). Pengaruh Reformasi Administrasi Perpajakan dan Pengetahuan Perpajakan Terhadap Tingkat Kepatuhan Pengusaha Kena Pajak. E-Jurnal Akuntansi Universitas Udayana, 5.2: h: 381-397. 
Rahayu, S. K. (2010). Perpajakan Indonesia : Konsep dan Aspek Formal, Yogyakarta : Graha IImu.

Rahayu, N. (2017). Pengaruh Pengetahuan Perpajakan, Ketegasan Sanksi Pajak dan Tax Amnesty Terhadap Kepatuhan Wajib Pajak, Akuntansi Dewantara. Vol. 1 No. 1.

Rufaedah, Y. dan Hadiani, F. (2015). Pengaruh Reformasi Administrasi Perpajakan Terhadap Kepatuhan Wajib Pajak Badan Pada KPP Pratama Se Bandung Raya, Sigma-Mu, Vol.7, No.1-Maret 2015.

Sekaran, Uma. (2003). Research methods for business.A skill building approach. New York : John Wiley \& Sons, Inc.

Soedibjo, S. Bambang. (2013). Pengantar Metode Penelitian. Bandung: Universitas Nasional PASIM.

Sugiyono. (2016). Metode Penelitian Kuantitatif Kualitatif dan $R \& D$ Cetakan ke-23. Bandung : Alfabeta.

Susilawai, K. E. dan Budiartha, K. (2013). Pengaruh Kesadaran Wajib Pajak, Pengetahuan Pajak, Sanksi Perpajakan, dan Akuntabiitas Pelayanan Publik pada Kepatuhan Wajib Pajak Kendaraan Bermotor. e-Jurnal Akuntansi Universitas Udayana. 4.2 Halaman : 345-357.

Yamane, Taro. (1967). Elementary sampling theory. Prentice-Hall, Inc. Englewood Cliffs, N.J. 